\title{
EL SUMINISTRO DE PRODUCTOS PETROLÍFEROS A LA REPÚBLICA EN GUERRA
}

\author{
GUILLEM MARTÍNEZ MOLINOS
}

\begin{abstract}
Este artículo constituye una aproximación al análisis de la estrategia adoptada por el Gobierno republicano para asegurar durante la guerra civil española el suministro continuo de productos petrolíferos con los que alimentar la maquinaria bélica y el sector de economía civil residual. Se apoya, fundamentalmente, en la documentación depositada en el Archivo General de la Cía. Arrendataria del Monopolio de Petróleos, S. A. (Campsa) al que el autor ha tenido acceso gracias a la colaboración de su dirección y al apoyo del B. de España. El testimonio de testigos directos ha contribuido a colmar una parte de las lagunas documentales encontradas en la investigación.
\end{abstract}

Un reciente trabajo expone el encuadramiento general de los suministros de derivados petroliferos en el contexto de la economía de guerra planteada en España a partir de la sublevación militar del verano de 1936 (1).

En síntesis, mientras el bando rebelde contó muy pronto con la inestimable cooperación de la multinacional petrolera The Texas Co., que puso a su disposición no sólo carburantes y lubricantes y aditivos, sino vitales medios de transporte y facilidades crediticias (2), la República se enfrentó con un vacío que hubo de salvar levantando «ex novo» un dispositivo logístico que financiará con los recursos auríferos del B. de España trasladados al exterior poco después del estallido del conflicto.

(1) Martínez Molinos, Guillem. El suministro de petróleo. Historia 16. La guerra civil: Economía de guerra. Tomo 16. Madrid, julio 1987.

(2) Los acuerdos de Campsa (Burgos)-Texaco, alcanzados en una reunión celebrada en San Sebastián el 3 de noviembre de 1936 por los representantes de las dos entidades, señores Arvilla y Brewster, fueron confirmados telegráficamente por Brewster el 6 de noviembre, una vez obtenida la aprobación del «Big Boss» Rieber, y por carta un día después. Además de garantizar el suministro de los productos previstos en el marco del contrato republicano vigente, introducirá dos cláusuras absolutamente vitales para la economía de guerra franquista: condiciones crediticias a coste nulo para Campsa que permitía el aplazamiento de los pagos hasta 90 dias fecha factura y la provisión de medios de transporte hasta que «Campsa estuviera en condiciones de procurárselos». 
Las primeras medidas prácticas del Gobierno para afrontar la situación, por lo que a los abastecimientos petroliferos se refiere siguen, por ahora, en la penumbra documental.

El dirigente socialista vasco Toribio Echevarría, en una de sus obras escritas y publicadas en el exilio, refiere que a mediados de agosto, cuando llevaba tres años alejado del negocio petrolero, recibió un radiocable de Madrid instándole a que se personara con toda urgencia en la oficina comercial parisina del comercio soviético de exportación de derivados petrolíferos Soiuzneftexport -coloquialmente Nafta Rusa-con el fin de conseguir la reanudación de los suministros, esta vez a la España en guerra (3).

La Nafta era un proveedor clásico del mercado español de carburantes y lubricantes desde antes incluso de la implantación del Monopolio en 1927. El último contrato en vigor, impulsado por el ministro de Hacienda, Indalecio Prieto, había sido denunciado por el primer Gobierno del bienio corrector. Los últimos cargamentos a su amparo habían llegado a puertos españoles meses antes de la sublevación.

Los primeros suministros soviéticos en las nuevas circunstancias no están bien recogidos en los fondos societarios consultados. La referencia documentada, más próxima al comienzo del conflicto, está datada el 12 de septiembre. Es un apunte contable, en un estadillo que Nafta Rusa remite a Campsa, por seguros acreditados por el buque-tanque (b/t) «Batun». No sabemos el tipo o coste de los productos servidos por ese moderno petrolero de la marina mercante soviética ni tampoco los puertos de carga y descarga. R. González Echegaray, citando a Salas Larrazábal, afirma que en el período comprendido entre el 15 de agosto al 15 de septiembre arribaron a puertos gubernamentales cuatro b/t soviéticos con 30.000 toneladas de productos. Según ese autor, el petrolero «Varlaam Avaneesov» descargó en Barcelona

(3) Torivio Echevarria (Eibar, 1887-Caracas, 1968), militante socialista e influyente miembro de la ejecutiva del PSOE; fue en una primera época oficial mayor del Ayuntamiento de su ciudad natal. En 1918 fundó allí la Soc. Coop. Obrera «Máquinas de Coser Alfa», que dirigiría entre 1923 y 1936 . Su valia profesional y probada honestidad debieron influir en Indalecio Prieto, ministro de Hacienda del Gobierno provisional de la República, que le propuso para el delicado puesto de delegado del Gobierno en Campsa. Entonces la Arrendataria estaba controlada por un sindicato de banqueros que reunía a la crema de la oligarquía financiera española y veía la llegada del nuevo régimen con la mayor suspicacia. Siguió como delegado en los sucesivos Gabinetes Azaña. En septiembre de 1933 presentó la dimisión, que le fue aceptada, al ministro Lasa, del Gobierno Lerroux, al inicio del llamado «bienio negro», reintegrándose a "Alfa», cuya gestión no había abandonado por completo. Tras la sublevación militar, el Gobierno de Largo Caballero, con el doctor Negrín como ministros de Hacienda, le nombró director gerente de Campsa, en cuya capacidad continuó hasta la caída de Barcelona. Fue también consejero del B. de España. Vid. Viaje por el país de los recuerdos, Méjico, Imp. Modernos, 1968; pp. 423 y 424 . 
una partida de gasolina en el mes de octubre. De estas expediciones la documentación no ha dejado rastro (4).

Parece lógico pensar que en las semanas siguientes a la sublevación los suministros siguieron las pautas del período precedente, por efecto del impulso inercial que caracteriza este tipo de tráficos. Por otro lado, et posicionamiento de los «partners" comerciales del Monopolio español hacia la situación por la que atravesaba su cliente peninsular se configuró con una cierta lentitud. Buen ejemplo de ello es el de The Texas Co., que, bien y tempranamente informada sobre los acontecimientos españoles, en primero de octubre de 1936 estaba cargando al «Campuzano» con gasolina automoción y especial de aviación en sus instalaciones de Port Arthur.

Toma de posición más temprana es la de la sociedad belga Petrofina, proveedor no habitual del Monopolio, que el 1 de agosto declina cargar en el b/t «Remedios» la partida contratada de gasoil alegando dificultades en la presentación del crédito irrevocable por la agencia parisina del B. de Bilbao, que Petrofina atribuye a las "graves circunstancias españolas actuales». El b/t «Remedios» abandonará el puerto rumano de carga - Constanza - en lastre y creemos que siguiendo instrucciones de la dirección se dirigirá a un puerto soviético del Mar Megro -Batoum-, en donde entre mediados y finales de agosto tomará productos sucios - gasoil y fueloil- con destino a un puerto republicano. En esta hipótesis sería el primer suministro soviético a la república acosada, al calor de los acuerdos Echevarría/Soiuzneftexport de mediados de agosto, de los que tampoco queda rastro documental.

Los principales efectivos de la flota mercante de altura del Monopolio siguieron en manos del Gobierno durante 1936. No fue hasta enero de 1937 que perdió precisamente al "Campuzano", primera unidad leal apresada o neutralizada por los sublevados en acción de guerra. No es por lo tanto aventurado pensar que inicialmente la responsabilidad de mantener los suministros recayera, como en el período de paz precedente, en las propias unidades, aplicadas mayoritariamente al trayecto Mar Negro/Mediterráneo, tripuladas por las dotaciones habituales y gobernadas por sus mandos naturales. El control por las nacionalistas del paso del Estrecho, a finales de septiembre de 1936, constituye un hito importante en el desarrollo de la guerra económica. A la amenaza a las líneas de suministro republicanas procedentes de Dccidente con destino a puertos mediterráneos, se unía la de los aprovisionamientos desde ese mismo litoral al Norte gubernamental. Para hacer frente a esta situación con las mejores garantías de éxito el abastecimiento petrolero a las

(4) González Echegaray, Rafael. La Marina Mercante y el tráfico marítimo en la guerra civil. Ed. S. Martín. Madrid, 1977, pg. 275. 
dos zonas geográficas en que había quedado el territorio republicano se antendería desde dos centros de suministros bien diferenciados: la zona Norte se alimentará básicamente con envíos originados en el Reino Unido o los EE.UU. y la zona Centro-Litoral mediterráneo, con derivados provenientes del Mar Negro. A lo largo del conflicto, partidas aisladas pero no por ello menos significativas de preciado carburante de aplicación militar de origen americano - gasolina automoción y especial para aviación - seguirán arribando a puertos mediterráneos controlados por el Gobierno.

La situación de incomunicación por tierra y de bloqueo por mar en que se encuentra el Norte de España impone nuevas soluciones que aparentemente el Gobierno de la nación tarda en hacer efectivas. El recién constituido Gobierno provisional de Euskadi, para garantizar la continuidad de los suministros militares y generales, emprende determinadas iniciativas de orden legal y práctico que interesan también al suministro petrolífero de su asediado territorio. La primera y quizá principal, en este contexto, es la creación el 26 de octubre de 1936 de un comité interventor ejecutivo de la Campsa al frente del cual nombra al militante nacionalista Vicente Senosain (5).

Los recuerdos de testigos presenciales tales como el del entonces jefe de la factoría de Santurce, Martín García Urziaga (MGU), son útiles para penetrar los entresijos de las acciones emprendidas por el ejecutivo vasco en sus primeras semanas de azarosa existencia y columbrar al mismo tiempo el grado de afectación de los resortes gubernamentales del poder central de la nación.

Según ha manifestado al autor MGU, abandonó su tierra - a finales de 1936 - a bordo de un destructor británico, siguiendo instrucciones de Senosain. Una vez en París se dispuso a establecer contacto con posibles suministradores de derivados petrolíferos cuando coincidió, por casualidad, con Germán Blix, agente de la oficina central de Campsa, que se encontraba en la capital francesa persiguiendo una misión similar.

Los dos empleados examinaron conjuntamente la situación planteada por el cerco del País Vasco y tomaron la decisión, después de consultar a Valencia, de comprar con cargo a la renta de petróleos una partida de fuel y gasolil soviético a la sociedad constituida en Londres Russian Oil Products (ROP).

(5) El decreto del Dto. de Hacienda (D. O. del País Vasco de 28 de octubre) creando el Comité Interventor va firmado por el presidente del Gobierno provisional Aguirre y por el consejero de Hacienda De la Torre. El comité que sustituye en sus funciones a los órganos administrativos de Campsa en el País Vasco está presidido por Vicente Senosain e integrado por Sarrasqueta (sindicalista vasco), Nadal (PSOE-UGT), Lacuesta, Echevarría, Azqueta e Ibáñez, estos tres últimos vocales del Consejo de Administración de Campsa en representación del Banco de Vizcaya, partícipe de la Arrendataria. 
El único b/t de bandera española no perteneciente al Monopolio de petróleos era el «Gobeo», de la Cía. Cantábrica de Navegación, preparado para el transporte de productos pesados como fueloil y asfaltos, amarrado entonces en el Nervión. Los dos hombres de Campsa, buenos profesionales, pasaron lista a las diferentes alternativas a su alcance y pensaron de inmediato en utilizar el buque. La solución «Gobeo» ofrecía la ventaja de ser rápida en su ejecución, además de discreta y económica. La contratación pública en el bullicioso mercado de fletes y seguros de Londres, exigía importantes medios de pago y estaba reñida con la debida reserva aconsejable para garantizar el buen fin de la operación de avituallamiento.

Por otra parte, elementos de la marinería y oficialidad del Dto. Marítimo de Campsa eran naturales del País Vasco, en donde la guerra les había sorprendido y allí permanecían como consecuencia del aislamiento del territorio. No era, pues, difícil reclutar una tripulación aguerrida dispuesta a burlar la vigilancia enemiga.

El b/t «Gobeo», tripulado con oficialidad y marinería de Campsa, conseguiría realizar durante el primer semestre de 1937 tres viajes ida y vuelta Londres-Bilbao, burlando el bloque franquista y transportando en cada uno 4.000 toneladas de combustible. La última partida, descargada en vísperas de la ocupación de la capital vasca por las brigadas navarras de Solchaga, fue devuelta al buque, con órdenes de hacerla arribar a Santander. En el trayecto el buque fue interceptado y apresado por un bou enemigo, que lo condujo a Pasajes.

Menos fortuna tuvo el otro intento de abastecimiento petrolífero de Euskadi recogido por la documentación (6).

La utilización de la flota propia, que soportaba el grueso del tráfico petrolero exterior de España hasta el inicio de la guerra, disminuye aceleradamente a medida que avanza el conflicto.

De las casi 200 expedidiones anotadas por el investigador, alrededor de una quinta parte lo fueron en barcos de la flota del Monopolio y el resto con barcos de pabellón extranjero, preferentemente británico, que contaba con la protección de su flota de guerra.

(6) El b/t «Campeador», con 10.000 ton. de gasolina automoción y aviación americana intentó en vano arribar a Bilbao en la primavera de 1937. Interceptado por una unidad enemiga logró burlarla izando pabellón inglés y haciéndose pasar por el «Pollux», un b/t de aquella nacionalidad. Se refugió en Burdeos, en donde fue secuestrado por un comando franquista con la supuesta complicidad del capitán, en circunstancias poco claras que fueron objeto de expediente por parte de la justicia republicana. Vid. Martínez Gil, Alfonso, La flota del Monopolio de Petróleos: 1927-1970, Delegación del Gobierno en Campsa. Madrid, 1971. También González Echegaray, op. cit., p. 131. 
A falta de una depuración de los listados de expediciones, la última operación de importación en b/t propio sería la que realizaba el «Campeador» cuando fue torpedeado en el Cabo Bonn el 12 de agosto de 1937 por la escuadra italiana, episodio bien recogido en la literatura.

A partir de esa fecha, los b/t que le quedan a la Cía. Arrendataria (serán hasta el final del conflicto "Campeche», "Campero" y «Zorroza») pasan a reforzar el puente marítimo Languedoc/Cataluña, a operaciones de cabotaje o a otros servicios. Desgraciadamente la documentación aflorada no arroja demasiada luz sobre las características del puente que enlazaba las terminales petroleras de los puertos de Sete y Le Nouvelle con el litoral catalán.

El hostigamiento enemigo sobre las vías de comunicación marítimas de la República tiene varias lecturas. Por un lado, la medida de las expediciones petroliferas neutralizadas por cualquier causa (menos de viente) parece corroborar la opinión de algunos autores que consideran cuantitativamente poco relevante el dominio franquista del mar en la neutralización del comercio exterior del Gobierno. Sin embargo, los buques aplicados al tráfico de hidrocarburos que fueron dañados o apresados una o varias veces a lo largo de la guerra serían aproximadamente la mitad de los más de sesenta contabilizados, entre b/t y mercantes convencionales, utilizados estos últimos en el importantísimo suministro de bidones con carburantes y lubricantes.

La relación de apresamientos y hundimientos en alta mar o en dársena por efecto de ataque naval, aéreo o campo de mina, con ser importante no afectó de forma esencial la estrategia global republicana, aunque sí le hizo adoptar soluciones cambiantes que le permitieron garantizar un máximo de operaciones no fallidas.

La política de reforzamiento de la flota, por reposición de bajas, se materializó a mediados de 1937 cuando la documentación da cuenta de la entrada en servicio de los b/t «Saustan» $y$ «English Tanker», cuyos propietarios eran respectivamente la propia Campsa y una empresa armadora domiciliada en Londres, constituida por impulso gubernamental, la Mid Atlantic Shipping Co. (7). El primer semestre de 1937 habia sido particularmente aciago para los barcos del pabellón propio, ya que había presenciado la desaparición definitiva o temporal del «Campeche», dañado por mina en el C. San Sebastián;

(7) La Mid Atlantic Shipping Co. se constituyó en Londres en el verano de 1937 y sus actividades se desarrollaron, seguramente, hasta después de concluida la guerra de España. Entre sus fundadores y directivos se encontraban el empresario norteamericano de origen vasco $\mathrm{Ma}$ rino de Gamboa y el abogado del Estado José Ignacio Aldama Gamir. Además de propietaria del b/t "English Tanker» desarrolló funciones de «broker», agente de fletes, etc. Esta sociedad, auspiciada previsiblemente por las autoridades republicanas - Gobierno provisional de Euskadi y Central- mereceria un estudio especializado. 
del "Campoamor», capturado en Burdeos; del "Campuzano», apresado, y del «Elcano», bombardeado en Gijón poco antes de la ocupación de Asturias.

A las dos citadas únidades se agregarían más tarde dos unidades más, el «lossifoglu» y el "Miocene», un b/t que se especializaría en el tráfico litoral entre La Nouvelle y Cataluña. Esta flotilla de navíos dispares tampoco resultó decisiva en la logística de Campsa, pero le añadió flexibilidad y ciertas dosis de autonomía. A finales de 1937/principios de 1938 el Monopolio se ha adaptado bien, por lo que a los transportes se refiere, a las nuevas circunstancias. Su tráfico resulta apenas alterado por acciones esporádicas del enemigo, que no volverán a alcanzar la virulencia del primer semestre. A señalar, con todo, los daños inflingidos por bombardeos a b/t atracados en puertos mediterráneos duramente castigados por la aviación enemiga, especialmente en la etapa final de la guerra.

La flota propia o ajena al servicio de Campsa cubre prioritariamente la ruta del Mediterráneo Oriental, con origen en las terminales petroleras soviéticas del Mar Megro (puerto de Batuum y Tovapse) y en el puerto rumano de Constanza.

También a mediados de 1937 se contratan los almacenes —colchón de productos blancos (gasolina y keroseno)- de Sete y La Nuovelle, que irán adquiriendo mayor importancia a medida que avanza la guerra y se acercan los frentes a la frontera francesa.

MGU refiere que centenares de camiones cisternas de propiedad francesa alquilados por la República a la sociedad Sogesud cubrian el trayecto La Nouvelle-Barcelona a lo largo de 1938 y principios de 1939. Las instalaciones de la sociedad Redeventza en Sete se especializará en la carga de $\mathrm{b} / \mathrm{t}$ del puente marítimo, aunque también éstos acuden ocasionalmente a La Nouvelle. Las operaciones de abastecimiento de los indicados almacenamientos del Mediodía galo son responsabilidad de la oficina de Campsa (Petróleos) en París, que funciona primero dentro del complejo Campsa-Gentribus para independizarse después.

La base documental contiene información relevante sobre los movimientos de importación por carretera, pero exige una mayor depuración que no ha sido posible realizar hasta ahora, al contrario de lo que ocrurre con la base de datos por vía marítima, mucho más perfilada y completa.

Determinadas navieras británicas, entre las que destaca con diferencia la Stanhope Steamship Co., propiedad de Billmeir, se especializarán en el arriesgado suministros a la República y, en los últimos días de la guerra, contribuirán a evacuar a la población agolpada en las localidades portuarias sitiadas por las tropas victoriosas de Franco. 
Se acompaña al presente artículo, como apéndice, un listado que recoge la toralidad de las expediciones marítimas, identificadas por el autor, con destino a puertos gubernamentales durante la guerra civil.

El interés de una relación como la que por primera vez se expone a la consideración de los estudiosos, estriba en su aportación a la cuantificación de las importaciones de productos petroliferos efectuadas por el Gobierno en el citado período, huérfano de estadísticas fiables y en muchos casos siquiera aproximadas.

Queda comentar finalmente la metodología seguida para su elaboración.

Se ha informatizado un fichero de suministros, para el período bélico, con diferentes compos (columnas) que se comentan más adelante. Cada asiento o línea constituye un registro del fichero que recoge el movimiento de un producto -fueloil, gasoil, gasolina automoción, etc- transportado por un buque en un viaje determinado. Las bodegas de un buque-cisterna están compartimentadas endiversos tanques de almacenamiento, de tal modo que una misma expedición puede reunir varios productos, que en todo caso pertenecen a una misma familia, de las dos existentes: productos limpios gasolinas, kerosenos, benzol-y productos sucios -crudo, fuel, gasoil, asfaltos-. Cada buque está especializado en el transporte de una familia y no suele cambiar su especialización a lo largo de su vida útil. Los lubricantes y grasas se transportaban en envases de diferentes características; en este tráfico intervenían tanto buques mercantes normales como los propios buques cisterna, que utilizaban unos compartimentos especiales aptos para carga general. Frecuentemente y en los dos bandos, una parte importante de gasolina especial de aviación, formulada para su consumo inmediato, se importaba en bidones de 200 litros, que servían asimismo para la carga de los aparatos en el propio campo de aviación, con la ayuda de pequeñas bombas de actuación manual. En los movimientos de bidones con carburantes intervenían, pues, prioritariamente, buques mercantes, de los que el listado que se adjunta da una buena muestra.

En consecuencia, a algunos viajes corresponden varios registros.

A partir del fichero o principal así formado se pueden recabar una variedad de ficheros auxiliares o de trabajo, secuenciados por campos. En esta ocasión se presenta el fichero por el campo de «suministradores», que se estima como el más representativo para apreciar la estructura de los suministros leales y permite asimismo calibrar su composición.

Los campos anotados han sido, por el orden en el que aparecen en el listado: 
Fecha de embarque: cuando se desconocía el día exacto, en especial a partir de 1938, se ha atribuido un número de orden dentro del mes en cuestión. Los dígitos expresan por este orden año, mes y día.

Proveedor: la República se suministró mayoritariamente de la Soc. Nafta soviética y de empresas rumanas; una multinacional americana, Atlantic, permaneció fiel a sus compromisos anteriores y facilitó al Gobierno lo que éste pudo buenamente retirar con sus propios medios; la Texaco, ligada asimismo por contrato con Campsa, cambió de bando en octubre/noviembre de 1936. En caso de ignorarse el suministrador, se hace constar con «N.D.». Los transbordos definen las operaciones de carga intermedias, bien de barco a barco en rada protegida - las menos- o de las instalaciones de almacenamiento-colchón que la República alquiló en Sete y La Nouvelle, en el litoral meridional galo.

Producto: se enumeran los derivados importados y, cuando ha sido posible, se han asentado productos no habituales, como el benzol, utilizado en las mezclas para la elaboración de combustible de aviación de alto octanaje, e incluso se han identificado las pocas partidas de crudo destinadas a la pequeña refinería catalana de Cornellá (antigua Sabadell \& Henry), que estuvo en funcionamiento durante casi todo el período bélico.

Buque y número de viajes: tras el nombre más utilizado de cada buque/tanque - los cambios de nombre y bandera eran frecuentes por razones obvias- se ha dispuesto un número de orden de los viajes realizados por esa unidad, que en los buques de la Arrendataria se corresponde con el número de orden de la serie original. Cuando se trata de una sola expedición, se indica con las letras UN.

Procedencia: el listado es especialmente poco explícito en este campo. El autor cree haber recogido todos los destinos a puertos del Cantábrico, bien el País Vasco, bien en Cantabria y Asturias. En esta hipótesis, todas las demás operaciones de importación arribaron a puertos mediterráneos, bajo control gubernamental, donde la Cía. Arrendataria disponía de estaciones de recepción. Cartagena, base de la flota leal, era lugar privilegiado para la recepción del fueloil. La documentación recoge con frecuencia expediciones que descargan en dos o más puertos.

Cantidades en Tm. e importes Fob en US $\$$ (fletes y seguros excluidos): se han anotado parámetros exactos cuando tales datos eran facilitados por el soporte documental; en caso contrario, y con finalidad estadística, se han dispuesto datos aproximados coherentes con el texto. 
Observaciones: además de enumerar las incidencias surgidas en una expedición, sea en tránsito o en rada, se han hecho llamadas en las expediciones sobre las que el representante de Texaco ante Franco, William M. Brewster, domiciliado en París, suministraba algún tipo de información a las autoridades, bien por iniciativa propia o a petición de aquéllas. Las operaciones que cuentan con más inteligencia son las originadas en Rumania, en donde proliferaba una constelación de sociedades vinculadas a intereses occidentales. Las fechas son las de las comunicaciones epistolares dirigidas por Brewster a Burgos.

Una profundización en los contenidos del propio archivo de Campsa o el acceso a otras fuentes documentales permitiria llenar los huecos evidentes del listado, en su presenciación actual.

Entre los que el investigador intuye se encuentran los siguientes:

- El puente Languedoc-Cataluña, tanto en su vertiente terrestre como en la marítima de cabotaje. Asimismo, los canales de aprovisionamiento a los almacenamientos-colchón del Languedoc.

- Los períodos inicial y final de la colaboración soviética, así como su articulación contractual. Los rastros documentales de los envíos soviéticos desaparecen a partir de agosto de 1938, pero hay indicios de que debieron continuar hasta finales de año.

La evaluación de los fondos aplicados a fletes/seguros y gastos de despacho de mercancias, primas, bonificaciones y demás extras. El Gobierno contrató fletes y seguros en condiciones onerosas; las recompensas a las navieras y a los capitanes que se aventuraban a realizar los viajes en las duras condiciones imperantes no eran raras, según testimonia MGU y refleja, siquiera parcialmente, la documentación. En ocasiones la componente de gastos por fletes y seguros podia superar el propio coste de los productos. Tampoco se conoce el precio de adquisición de los buques comprados por cuenta del Monopolio ni la reparación de los daños y averías causados a su flota.

Los cómputos globales de importación de crudo y productos por vía marítima por el Gobierno republicano durante la guerra civil arroja las siguientes cantidades:

- Movimientos: 190.

- Tonelaje: 1.165.000.

- Coste: US \$26.300.000. 
Una valoración "sui generis» de las lagunas elevaría esas cifras alrededor de un 20 por ciento, quedando como montantes finales, razonables y estimados, los siguientes:

- Movimientos: 230.

- Tonelaje: 1.400 .000 .

- Coste: US \$31.000.000.

La URSS habría contribuido con algo más de un tercio de los suministros, esto es, 425.000 toneladas ( 570.000 ton. con la mayoración), destacando por lo tanto como el proveedor más importante.

Los nacionalistas importaron por vía martítima durante la guerra civil una cantidad similar: alrededor de un millón y medio de toneladas de productos derivados del petróleo y de aditivos, aplicando en su adquisición unos US $\$ 24.000 .000$ Fob. La Texaco facilitó - nunca mejor empleada la expresiónlas tres cuartas partes, esto es, 1.100 .000 toneladas, con una contrapartida económica de unos 20 millones de dólares.

En conjunto, la economía de guerra española absorbió unos tres millones de toneladas de derivados petroliferos, empleando algo más de US $\$$ 55.000.000 Fob.

De acuerdo con los grandes números elaborados por el autor, las importaciones españolas de productos derivados durante los casi tres años de guerra mantuvieron la tónica del período inmediato precedente, que era de casi un millón de toneladas anuales. Donde se registran sustanciales variaciones es en la estructura de los suministros, en los costos de adquisición y, obviamente, en los modos de utilización, que supusieron un desvio importantísimo de recursos energéticos hacia factores bélicos y parabélicos. 

ANEXO 


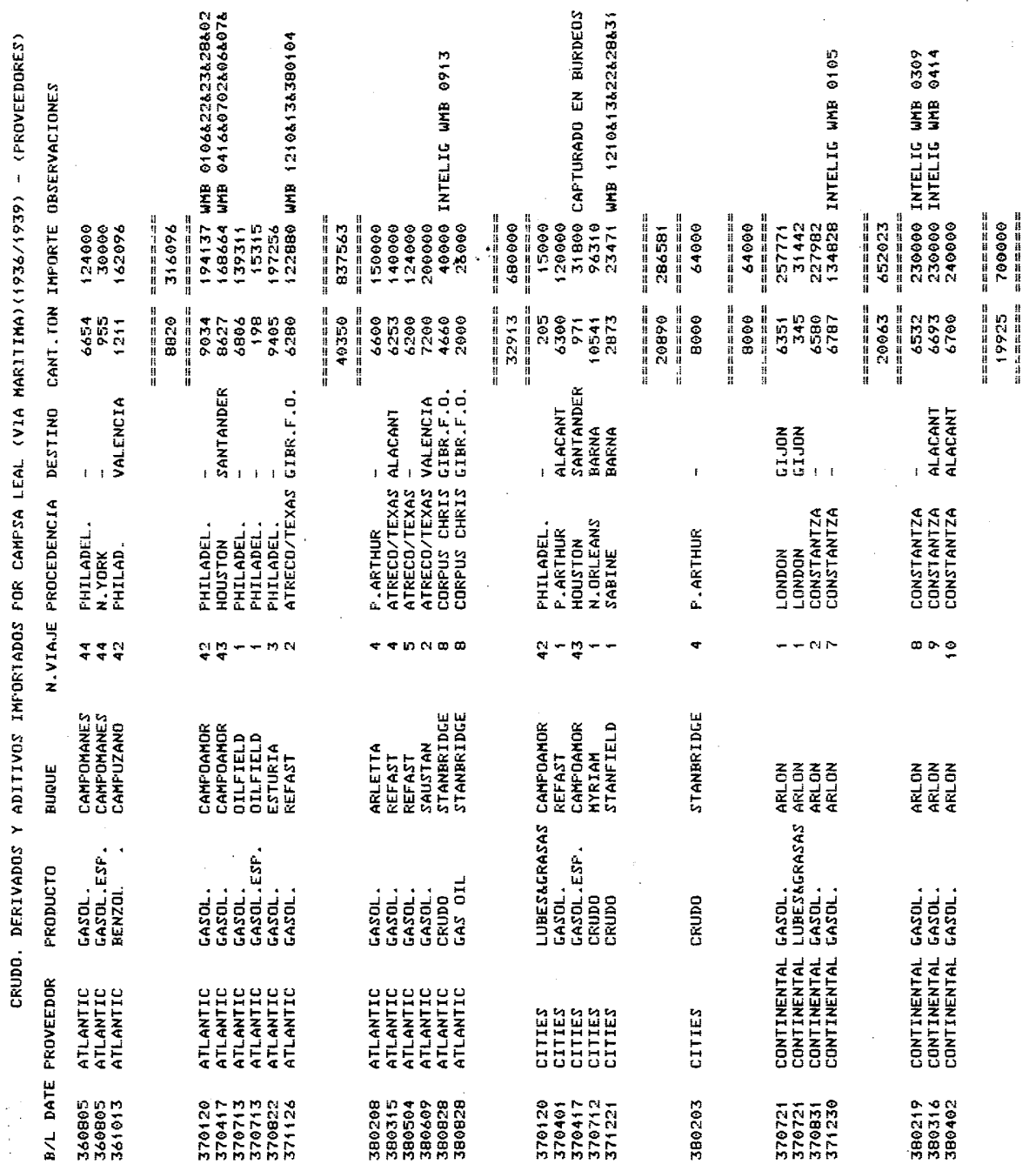




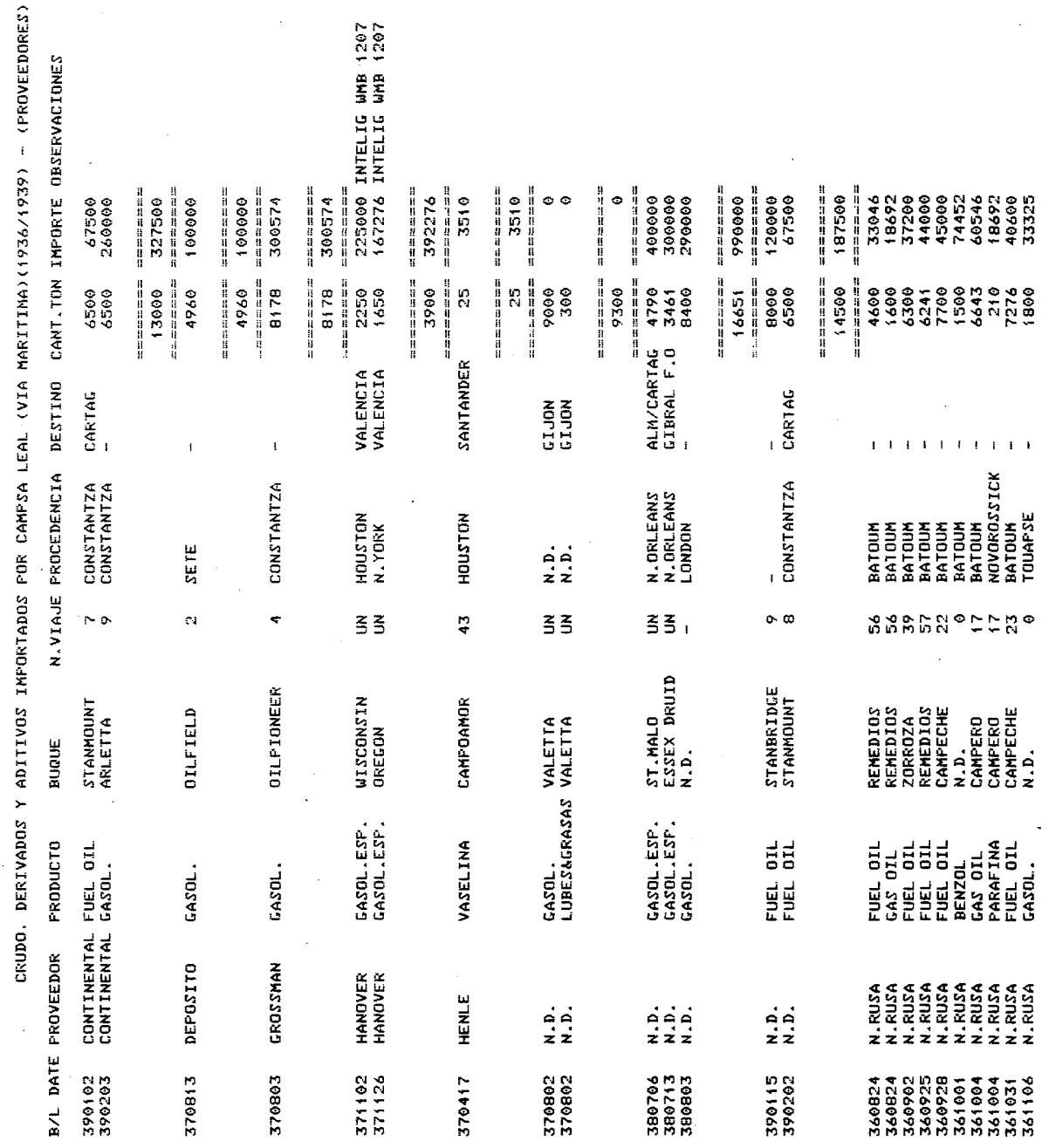




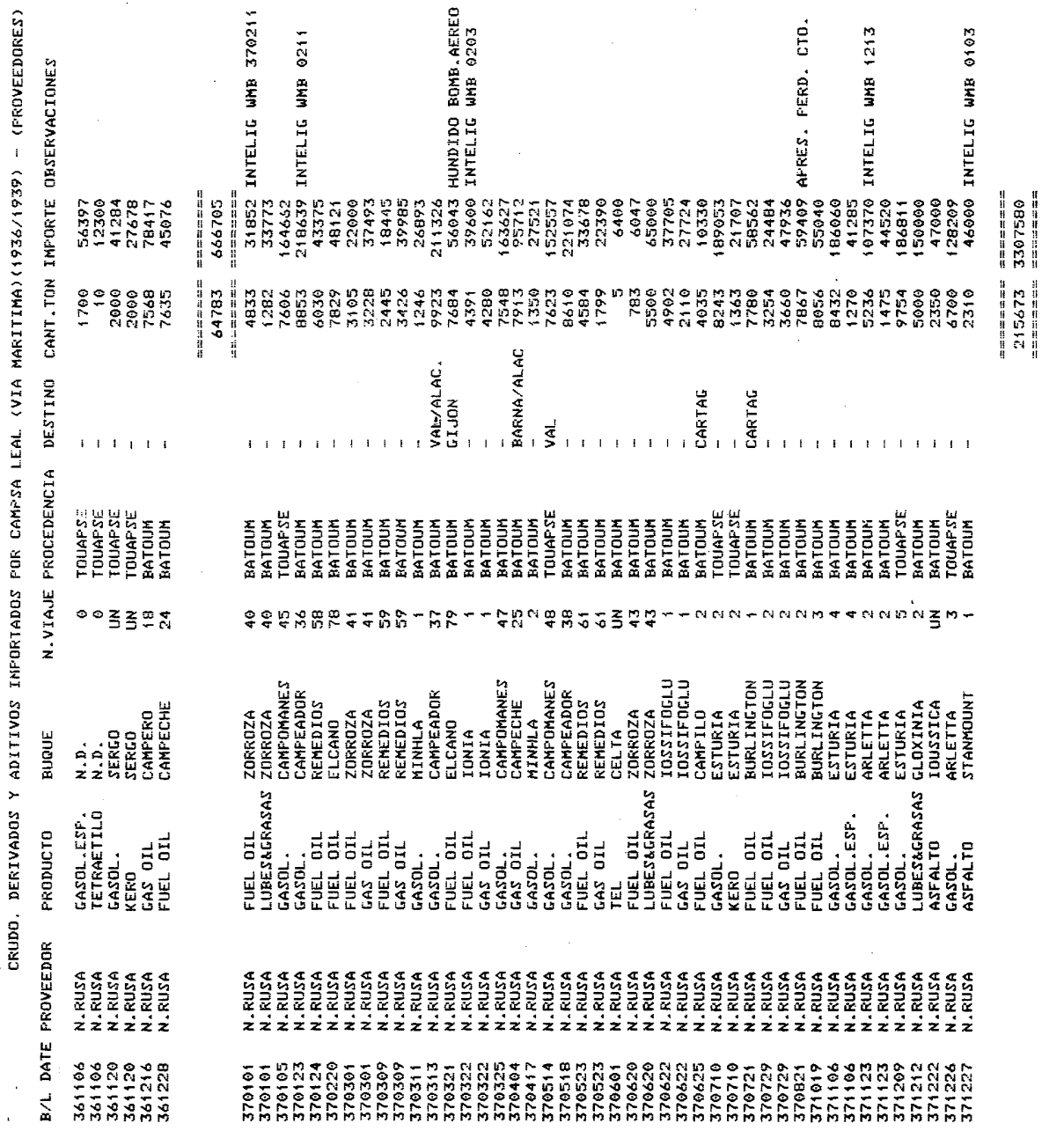




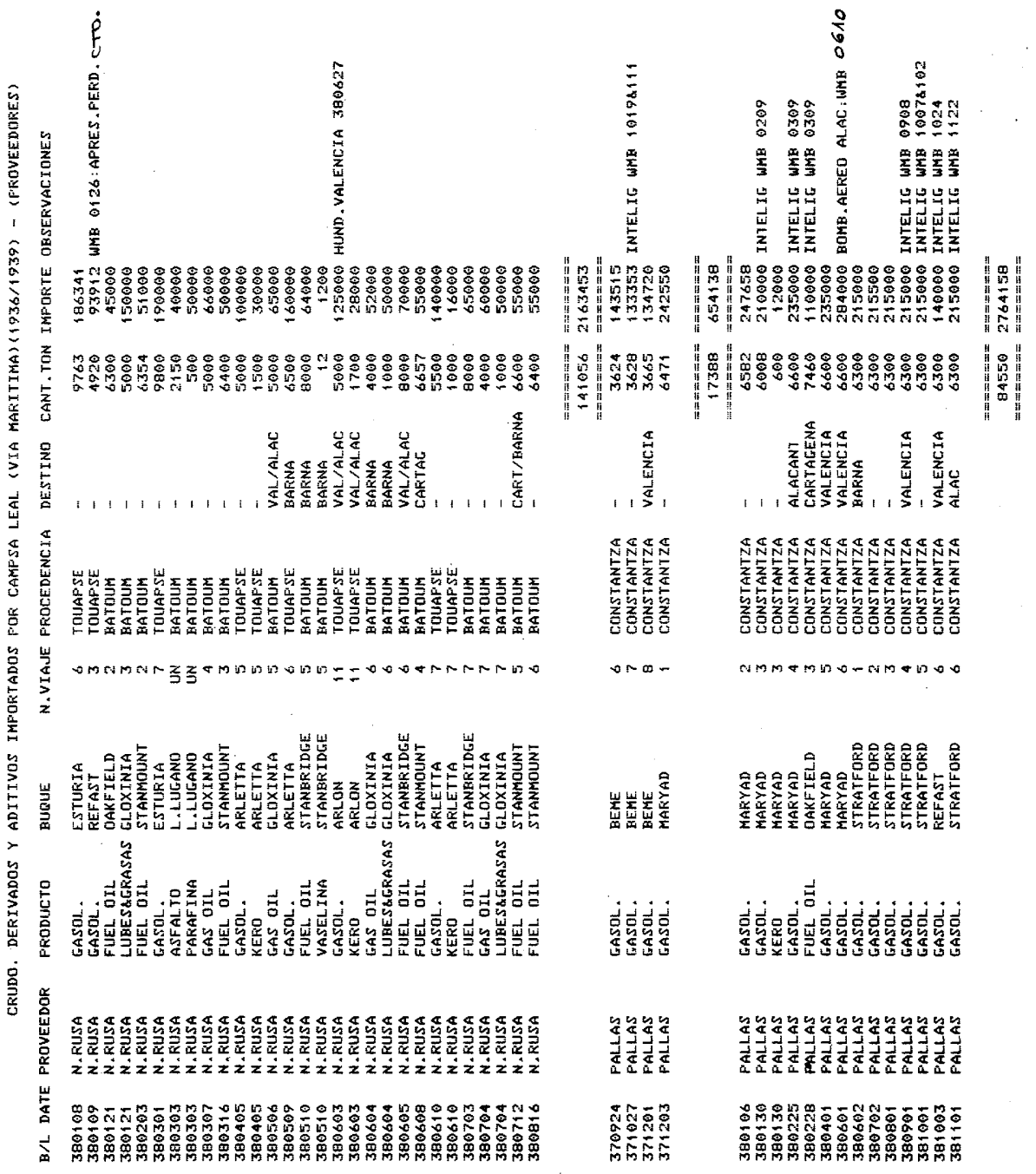




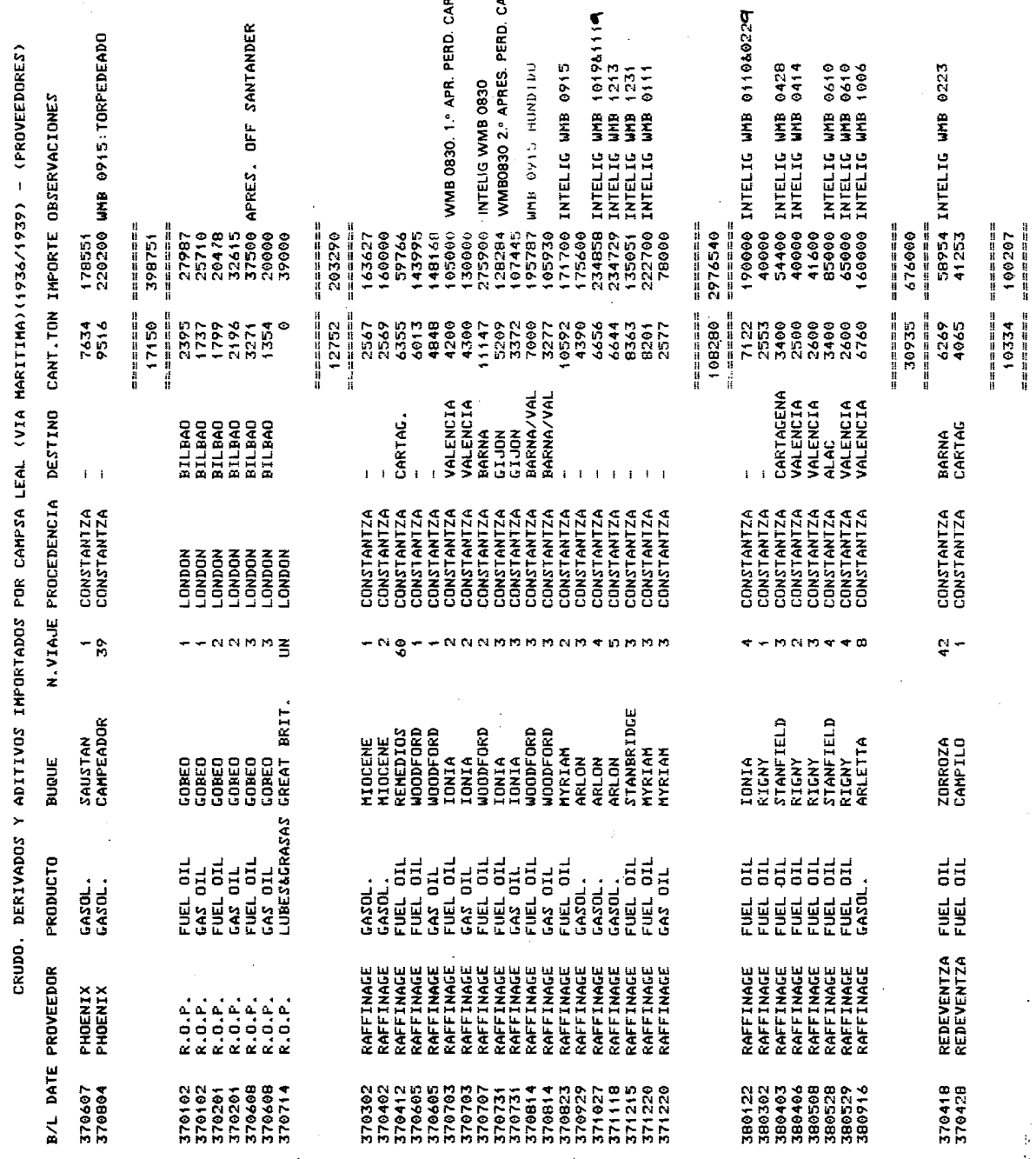




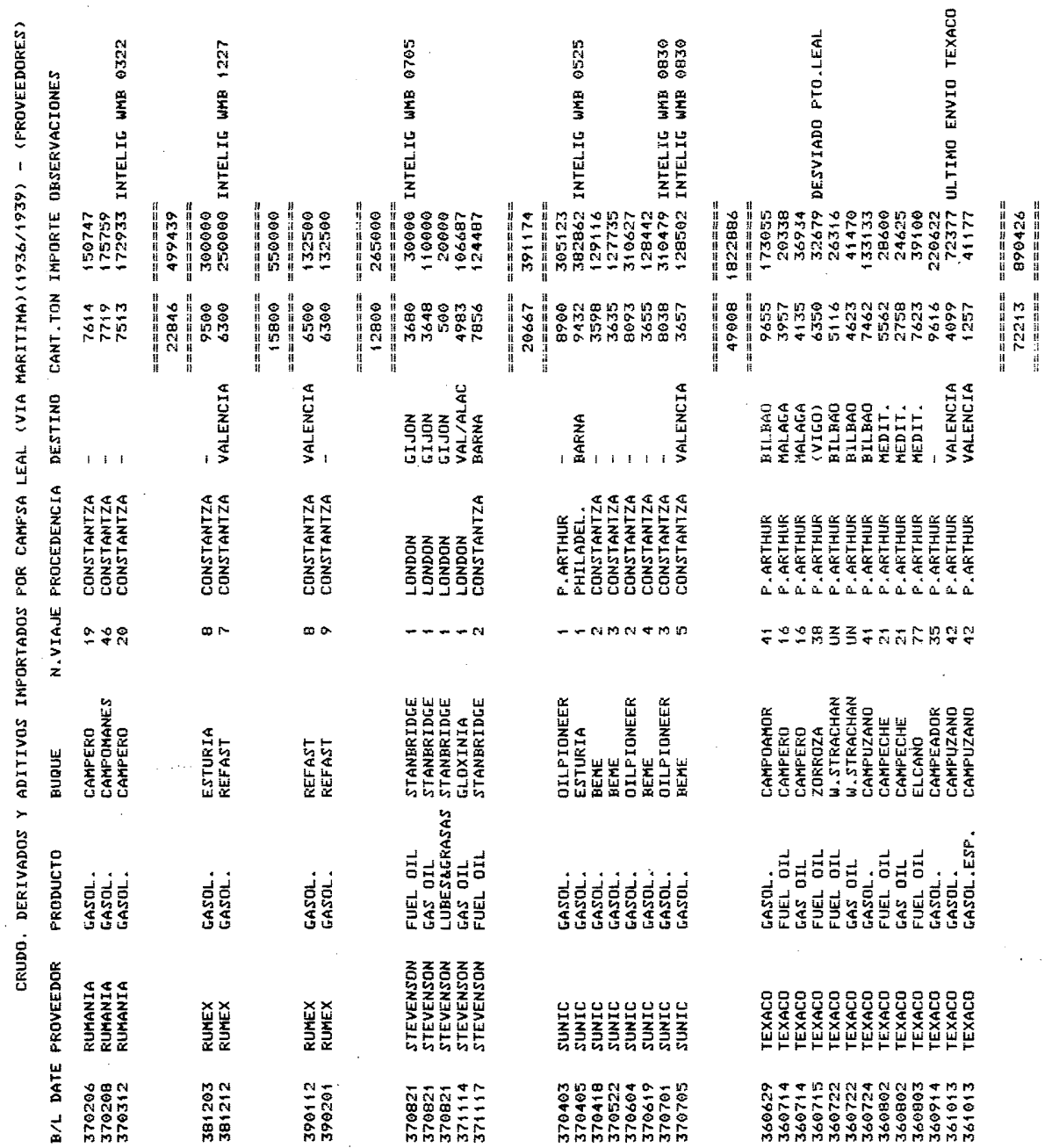




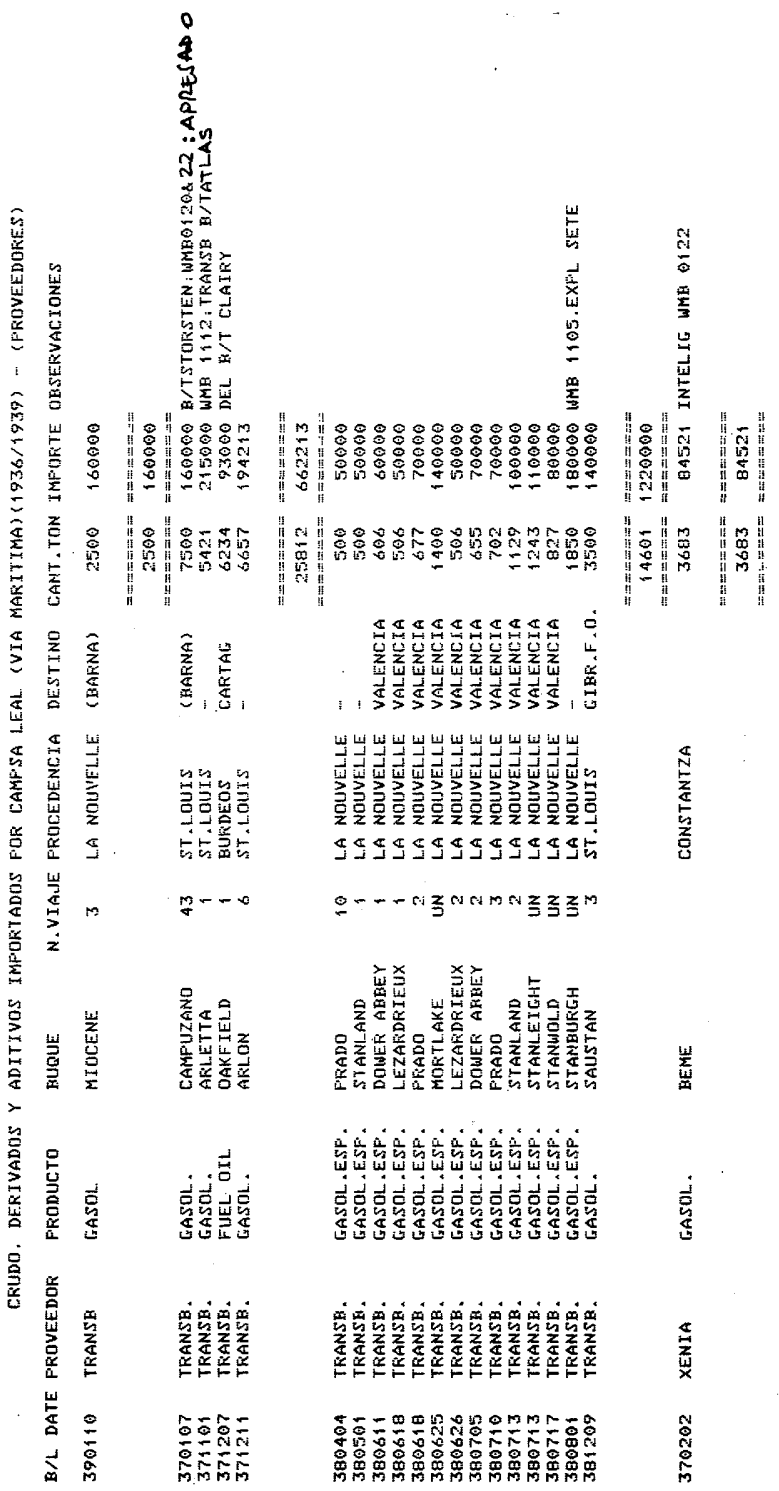

